\title{
"Factors affecting hospital admission and recovery stay duration of in-patient motor victims in Spain"
}

Miguel Santolino, Catalina Bolancé and Manuela Alcañiz 


\title{
$\oplus_{\circledast}|| R|E| A \mid$
}

Institut de Recerca en Economia Aplicada Regional i Pública Research Institute of Applied Economics

\section{Universitat de Barcelona}

\author{
Av. Diagonal, $690 \bullet 08034$ Barcelona
}

WEBSITE: www.ub.edu/irea/•CONTACT: irea@ub.edu

The Research Institute of Applied Economics (IREA) in Barcelona was founded in 2005, as a research institute in applied economics. Three consolidated research groups make up the institute: AQR, RISK and GiM, and a large number of members are involved in the Institute. IREA focuses on four priority lines of investigation: (i) the quantitative study of regional and urban economic activity and analysis of regional and local economic policies, (ii) study of public economic activity in markets, particularly in the fields of empirical evaluation of privatization, the regulation and competition in the markets of public services using state of industrial economy, (iii) risk analysis in finance and insurance, and (iv) the development of micro and macro econometrics applied for the analysis of economic activity, particularly for quantitative evaluation of public policies.

IREA Working Papers often represent preliminary work and are circulated to encourage discussion. Citation of such a paper should account for its provisional character. For that reason, IREA Working Papers may not be reproduced or distributed without the written consent of the author. A revised version may be available directly from the author.

Any opinions expressed here are those of the author(s) and not those of IREA. Research published in this series may include views on policy, but the institute itself takes no institutional policy positions. 
Hospital expenses are a major cost driver of healthcare systems in Europe, with motor injuries being the leading mechanism of hospitalizations. This paper investigates the injury characteristics which explain the hospitalization of victims of traffic accidents that took place in Spain. Using a motor insurance database with 16,081 observations a generalized Tobit regression model is applied to analyse the factors that influence both the likelihood of being admitted to hospital after a motor collision and the length of hospital stay in the event of admission. The consistency of Tobit estimates relies on the normality of perturbation terms. Here a semi-parametric regression model was fitted to test the consistency of estimates, concluding that a normal distribution of errors cannot be rejected. Among other results, it was found that older men with fractures and injuries located in the head and lower torso are more likely to be hospitalized after the collision, and that they also have a longer expected length of hospital recovery stay.

JEL classification: C24, I10.

Keywords: Body injuries, Heckit estimator, semi-parametric estimator, Hausman test.

Miguel Santolino. RFA Research Group-IREA. Department of Econometrics. University of Barcelona, Av. Diagonal 690, 08034 Barcelona, Spain. E-mail: msantolino@ub.edu

Catalina Bolancé. RFA Research Group-IREA. Department of Econometrics. University of Barcelona, Av. Diagonal 690, 08034 Barcelona, Spain. E-mail: bolance@,ub.edu

Manuela Alcañiz. RFA Research Group-IREA. Department of Econometrics. University of Barcelona, Av. Diagonal 690, 08034 Barcelona, Spain. E-mail: malcaniz@ub.edu

\section{Acknowledgements:}

The authors are grateful to the Spanish Ministry of Education and Science for the support received and FEDER grant ECO2008-01223. 


\section{Introduction}

Healthcare expenditure is increasing rapidly in advanced societies. Over the last three decades healthcare spending in developed countries has grown on average 2.5 times faster than GDP (Hagist and Kotlikoff, 2009), and this trend is not expected to change in the near future. The reasons for this include an ageing population, advances in medical technology (their cost), and the defence strategies applied by medical practitioners to avoid malpractice liability. Although only a small proportion of the population will require hospitalization in any given year, hospitalization costs are one of the most significant annual healthcare cost drivers in healthcare systems. PeekAsa et al. (2011) estimate that annual hospital charges exceed \$1 billion in the USA, with the median hospital charge being above $\$ 25,000$. These hospitalization expenditures account for nearly one third of all medical expenses for the non-institutionalized population in the USA (Machlin and Carper, 2007). A high percentage of hospitalizations are the consequence of motor collisions. In Europe road traffic-related hospitalizations are the leading mechanism of injuries requiring hospitalizations (Segui-Gomez et al., 2008).

The goal of this paper is to explore the relationship between the injury characteristics and hospital stay duration of motor victims in Spain. In the road safety literature, studies that link injury characteristics and hospital stay duration have traditionally dealt with hospital data (Guria, 1990; Forman et al., 2011; Peek-Asa et al., 2011), and their results are therefore limited to hospitalized motor victims. Given that inpatient victims could be systematically different from those who are not admitted to hospital, any conclusions drawn from these studies cannot be extrapolated to all motor collision victims. This is relevant because most victims injured in a collision do not require hospitalization. This paper deals with motor victims involved in collisions irrespective of whether hospitalization was required or not. It will therefore be possible to investigate the factors that explain hospital duration from an unconditional perspective.

The analysis is based on a Spanish motor insurance database related to motor collisions involving injury victims. The data provide details of how injuries may develop after collision. Data are censored where hospitalization duration is only observed if the victim was admitted to hospital. A sample selection regression model is applied to determine the factors that affect both the hospital admission of traffic accident victims and the length of hospital stay in the event of admission. This methodology allows for the dependence of perturbation terms of both procedures. Modelling approaches that ignore dependence between hospital admission and recovery stay length would lead to biased parameter estimates, when such dependence exists (Cameron and Trivedi, 2005). 
Sample selection regression models have been widely applied in the road safety literature (Goldstein, 1986; Anastasopoulos et al., 2008; Tarko and Azam, 2011, Farah et al., 2009). Here a generalized Tobit regression is fitted in order to model the duration of hospitalization. The reliability of Tobit estimators is based on distributional assumptions. Unlike least square estimates for uncensored data, Tobit estimators are not consistent if errors are not normally distributed (Mashtare Jr. and Hutson, 2011). Consequently, the hypothesis of a normal distribution of errors must be tested when the Tobit regression model is applied. To our knowledge, however, the Tobit normality hypothesis has not been previously tested in road safety applications. In this paper a semi-parametric regression model is estimated in order to test the distributional assumption of normality. The Hausman specification test is then computed so as to compare Tobit estimators which are only consistent estimators under the null hypothesis of normality - with semiparametric estimators, which are consistent estimators under both hypotheses (Newey, 1987; 1999; 2009).

The structure of the paper is as follows. Section 2 presents the main characteristics of parametric and semi-parametric selectivity regression models, and outlines the utility of semi-parametric methods to test distributional assumptions. In section 3, an empirical application using a Spanish database is presented. This is followed by discussion and interpretation of the results. Concluding remarks are summarized in Section 5.

\section{Statistical analysis}

Hospital admission and length of stay of in-patients may be interpreted as a sample selection issue. First, medical practitioners examine the victim and decide whether admission to hospital is required. If so, the length of the hospital stay will depend on multiple factors including the physical condition of the victim and the type and severity of injuries. This section briefly describes both parametric and semi-parametric sample selection regression models. First, we describe the most popular parametric sample selection model, namely the generalized Tobit regression model, before moving on to consider Newey's semi-parametric regression model. The Hausman test is then discussed as a way of selecting the preferred model specification. 


\subsection{Generalized Tobit regression model}

The Tobit regression model (Tobin, 1958) has been widely used in the social sciences, and is applied when the range of the dependent variable is censored. Censoring occurs if data show a lower threshold (left-censored) below which the observed value of the variable always takes the value of the threshold. A similar interpretation holds for data with an upper threshold (rightcensored), although applications with left-censored data are more common. An extensive survey of Tobit regression models is provided by Amemiya (1984). Let $y$ be our outcome of interest, which is the length of hospital stay of the injury victim after a collision. The outcome $y$ is observed only if $y^{*}>0$, where $y^{*}$ is a latent (unobserved) variable. In our application $y^{*}$ indicates the hospital admission decision. The generalized Tobit regression model is specified as follows:

$$
\begin{aligned}
& y_{i}^{*}=z_{i}^{\prime} \gamma+u_{i} \\
& y_{i}=x_{i}^{\prime} \beta+\varepsilon_{i}
\end{aligned}
$$

for the $i$-th individual, $i=1 \ldots N$, where $z_{i}$ and $x_{i}$ are vectors of regressors, $\gamma$ and $\beta$ are vectors of parameters, and $u_{i}$ and $\varepsilon_{i}$ are normally distributed random errors with mean equal to zero and variance $\sigma_{1}^{2}$ and $\sigma_{2}^{2}$, respectively. Errors are correlated with covariance equal to $\sigma_{12}$. The observed variable is $I$ which is related to $y^{*}$ according to:

$$
I_{i}=\left\{\begin{array}{l}
1 \text { if } y_{i}^{*}>0 \\
0 \text { if } y_{i}^{*} \leq 0
\end{array},\right.
$$

where $I_{i}$ takes the value 1 when the $i$-th victim is admitted to hospital and 0 otherwise. One may put $\sigma_{1}^{2}=1$ without any loss of generality, since only the sign of the latent variable is observed. In Amemiya's terminology (1984) this model is referred to as the type II Tobit regression model. Heckman (1976) suggested a procedure to estimate parameters in two steps. Following this procedure, also called the Heckit estimator, a probit model regression of $I$ on $Z$ is firstly estimated. In the next step an additional regressor is included in the second equation in (1) to account for bias due to non-random sampling. $\beta$ and $\sigma_{12}$ may then be estimated by ordinary least squares (OLS) techniques applied to the extended regression model:

$$
\begin{aligned}
y_{i} & =x_{i}^{\prime} \beta+\sigma_{12} \lambda_{i}+\eta_{i} \\
& =x_{i}^{\prime} \beta+\sigma_{2} \rho \lambda_{i}+\eta_{i}
\end{aligned}
$$


such that the Heckman-type lambda is $\lambda_{i}=\phi\left(z_{i}^{\prime} \gamma\right) / \Phi\left(z_{i}^{\prime} \gamma\right)$, where $\phi(\cdot)$ and $\Phi(\cdot)$ are the standard normal density and distribution functions, and $\rho$ is the error correlation, $\rho=\sigma_{12} / \sigma_{2}$. The error variance $\sigma_{2}^{2}$ may be estimated by the following expression: $\hat{\sigma}_{2}^{2}=N_{1}^{-1} \sum_{i}^{N_{1}}\left[\hat{\eta}_{i}^{2}+\hat{\sigma}_{12}^{2} \hat{\lambda}_{i}\left(\hat{\lambda}_{i}+z_{i}^{\prime} \hat{\gamma}\right)\right]$, where $\hat{\lambda}_{i}=\phi\left(z_{i}^{\prime} \hat{\gamma}\right) / \Phi\left(z_{i}^{\prime} \hat{\gamma}\right)$ and $N_{1}$ is the number of victims admitted to hospital (Cameron and Trivedi, 2005).

To test hypotheses, an estimator of the asymptotic covariance of coefficients is required. Note that the disturbance term in (2) is heteroscedastic due to sample selection correction. Additionally, the unknown $\gamma$ is replaced by a vector of estimated parameters. OLS standard errors have to be corrected to account for these particularities. An estimator of the asymptotic covariance matrix is provided by Heckman (1979) and Greene (1981). The covariance matrix may also be estimated by means of bootstrapping techniques, as provided by most commercial statistical software.

\subsection{Semi-parametric regression model}

Statistical consistency of the Heckit estimator is based on the normality assumption of the perturbation term $u$. If $u$ is not normally distributed then $\lambda \neq \phi\left(z^{\prime} \gamma\right) / \Phi\left(z^{\prime} \gamma\right)$. The model (1) is consequently misspecified and OLS techniques in (2) lead to inconsistent estimates. Newey (2009) suggests a model estimation method in which the functional form of the selection correction is now unrestricted. He showed that this estimation procedure then gives consistent estimates of $\beta$ even if $u$ is not normally distributed.

Like the Heckman procedure the Newey estimation method involves two steps. In the first step Newey (2009) suggests estimating the parameter vector $\gamma$ by semi-parametric techniques as an alternative to fitting a probit regression model. Let us denote the semi-parametric estimator by $\hat{\hat{\gamma}}$. Newey argues that the semi-parametric estimator provided by Klein and Spady (1993) gives the

most efficient estimator, such that $\hat{\hat{\lambda}}_{i}=h\left(\hat{v}_{i}\right)$ where $\hat{v}_{i}=z_{i} \hat{\hat{\gamma}}$. In the second step, the vector of parameters $\beta$ is estimated from the following linear regression:

$$
y_{i}=x_{i}^{\prime} \beta+\hat{\hat{\lambda}}_{i}+w_{i}=x_{i}^{\prime} \beta+h\left(\hat{v}_{i}\right)+w_{i} .
$$


The unknown function $h(\cdot)$ may be approximated by power series. Let $\tau\left(\hat{v}_{i}\right)=\hat{\tau}_{i}$ be a monotonic transformation of $\hat{v}_{i}$ and $p^{K}\left(\hat{\tau}_{i}\right)=\left(p_{1}\left(\hat{\tau}_{i}\right), \ldots, p_{K}\left(\hat{\tau}_{i}\right)\right)^{\prime}$, where $p_{j}\left(\hat{\tau}_{i}\right)=\hat{\tau}_{i}^{j-1}$. The unknown function $h\left(\hat{v}_{i}\right)$ may then be approximated by means of a linear combination of the elements of $p^{K}\left(\hat{\tau}_{i}\right)$. The shape of the approximation function is based on the $K$ value, where the effect of the sample information increases with $K$. Given a $K$ value, the model $(3)$ is then defined as,

$$
y_{i}=x_{i}^{\prime} \beta+\delta_{1} p_{1}\left(\hat{\tau}_{i}\right)+\ldots+\delta_{k} p_{K}\left(\hat{\tau}_{i}\right)+w_{i}
$$

where the unknown function is approximated by $\hat{h}\left(\hat{v}_{i}\right)=\hat{\delta}_{1} p_{1}\left(\hat{\tau}_{i}\right)+\ldots+\hat{\delta}_{k} p_{K}\left(\hat{\tau}_{i}\right)$, and $\hat{\delta}_{1}, \ldots, \hat{\delta}_{k}$ are the OLS estimates in (4). In this study we consider $\hat{\tau}_{i}=\phi\left(\hat{v}_{i}\right) / \Phi\left(\hat{v}_{i}\right)$, which is one of the three alternative monotonous transformations suggested in Newey's paper. Similarly to Heckman (1976), Newey (2009) provides an estimator of the asymptotic covariance matrix of the vector of $\beta$ estimates.

\subsection{Testing normality}

The hypothesis of normality is tested by means of the well-known Hausman test, which is applied in order to compare two estimators of the parameters of a regression model. Under the null hypothesis both estimators are consistent but only one of them is efficient. Under the alternative hypothesis, however, only the non-efficient estimator is consistent. In our application we showed that the Heckit estimator is inconsistent if $\lambda \neq \phi\left(z^{\prime} \gamma\right) / \Phi\left(z^{\prime} \gamma\right)$. By contrast, the Newey estimator is consistent under both hypotheses, although it is less efficient than the Heckit estimator under the null hypothesis. Therefore, the hypothesis test is defined as follows, $H_{0}: \lambda=\frac{\phi\left(z^{\prime} \gamma\right)}{\Phi\left(z^{\prime} \gamma\right)} ; H_{1}: \lambda \neq \frac{\phi\left(z^{\prime} \gamma\right)}{\Phi\left(z^{\prime} \gamma\right)}$

Let $\hat{\beta}_{H}$ be the two-step Heckman estimator of the model (2) and $\hat{\beta}_{N}$ be the two-step semiparametric estimator of the regression equation (4). Under $H_{0}$ both $\hat{\beta}_{H}$ and $\hat{\beta}_{N}$ are consistent estimates but $\hat{\beta}_{H}$ is more efficient. However, only $\hat{\beta}_{N}$ is consistent under $H_{1}$. The Hausman statistic is computed as $T=\left(\hat{\beta}_{H}-\hat{\beta}_{N}\right)^{\prime}\left[\operatorname{Var}\left(\hat{\beta}_{N}\right)-\operatorname{Var}\left(\hat{\beta}_{H}\right)\right]^{-1}\left(\hat{\beta}_{H}-\hat{\beta}_{N}\right)$, which is $\mathrm{x}^{2}$ distributed 
under the null hypothesis with $p$ degrees of freedom, where $p$ is the number of parameters in the vector $\beta$ without the constant term.

In accordance with Amemiya (1984), the parameters in model (1) may also be estimated by maximum likelihood (ML). Although the ML estimator is more efficient than the Heckit estimator, its consistency depends on the hypothesis of binormality of errors. Unfortunately, it is not easy to test binormality in regression models with limited dependent variables (Lee, 1984; Lucchetti and Pigini, 2011). Unlike the ML estimator, however, bivariate normality of errors is not required in the Heckman procedure. The assumption in the Heckman procedure is that $\varepsilon$ is linearly regressed on $u$, where $u$ follows a standard normal distribution. The Heckit estimator has the additional advantage of being consistent in the event of jointly normal distributed errors. Therefore, the Heckman procedure would also be an adequate procedure when there is binormality of errors.

\section{Spanish database}

The data consist of a random sample of 16,081 non-fatal victims involved in traffic collisions in Spain. The database was provided by a Spanish motor insurance company. Information included in the database was recorded by the insurer during the processing of claims in order to track them until settlement. All of the victims suffered at least one day of temporary disability. Insurance databases provide information related to the injury consequences of collisions, but limited information on the circumstances of the collision. According to Spanish motor law, drivers who are at fault in the collision are not entitled to compensation. Consequently, the insurance company did not record injury information of at-fault drivers, and this was not included in the database.

Our goal here is to model the length of hospital stay of victims involved in motor collisions. The duration of hospital stay is observed for all the sample victims. Victims must be fully recovered or with stable injuries, and therefore discharged from hospital, before being compensated by the insurer. Sample casualties were compensated for personal damages by the insurer in the year 2007 , although the motor collision may have occurred before that year. Specifically, 28 per cent of collisions took place in 2007, 57 per cent in 2006, 13 per cent in 2005, and 2 per cent in 2004 or before.

The distribution (both unconditional and conditional) of the number of days in hospital for our data is presented in Figure 1. The mean length of hospital stay for sample victims is 2.10 days, with a standard deviation of 13.85 and median value of 0 . More than 87 per cent of sample victims were 
not admitted to hospital after the collision. Specifically, 1,999 sample victims had to be admitted to hospital after the collision. For those victims who were admitted to hospital, the conditional distribution of the length of stay is strongly asymmetric (Figure 1). The mean stay in hospital for inpatients is 16.87 days, with a standard deviation of 35.97 and median value of 7 days.

Figure 1. Histogram for the number of days in hospital

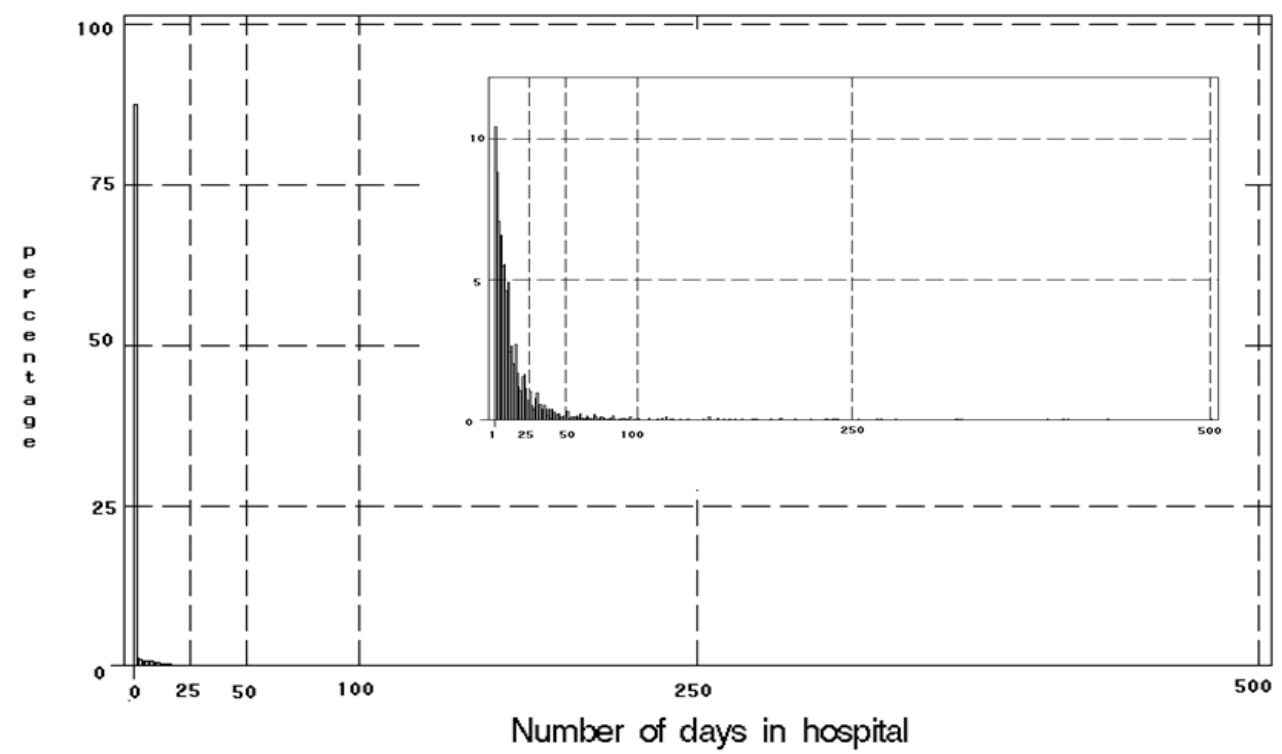

Note: Histogram of the hospital recovery time required by motor victims (in days). Inset: histogram of the hospital recovery time (in days) for those victims who were hospitalized.

The dependent variable of the model regression specification is the number of days in hospital, on a natural logarithmic scale. The indicator variable that records whether the victim was admitted to hospital after the collision and the logarithm of the number of days in hospital are regressed on the same set of explanatory variables. The description of variables and main statistics are shown in Table 1. Explanatory variables are classified into three groups: general factors, factors related to the region of the body that was injured and factors describing the nature of the injury.

General factors include information of the at-fault driver, such as his/her age. A number of authors have shown a link between driver age and the frequency and severity of motor crashes. This finding has been associated with the fact that young drivers are prone to more risky driving behaviour, whereas older drivers are more likely to have slower reaction times (Neyens and Boyle, 2008; Huang et al., 2008; Abdel-Aty et al., 1998). Other general factors cover attributes of 
the victim, such as gender and age, and information related to the type of victim. The effect of gender on severity is ambiguous. Many crash severity studies have found that females involved in motor collisions suffer more serious injuries than do males (Rifaat and Tay, 2009; Evans, 2001; Kockelman and Kweon, 2002), whereas other authors suggest that males are involved in more serious crashes (Tay and Rifaat, 2007; Valent et al., 2002). The extant literature indicates that the victim's age positively influences the frequency and severity of injuries (O'Donnell and Connor, 1996; Delen et al., 2006; Boucher and Santolino, 2010), although some studies have found a nonlinear relationship between age and severity (Newgard, 2008). Regarding the type of victim, a distinction is made between driver, passenger and non-motorized road user. The seating position of the victim has likewise been related to the severity of injuries (Smith and Cummings, 2004; Newgard et al., 2005). The crash severity behaviour of non-motorized road users has also been extensively investigated (Chong et al., 2010; Tarko and Azam, 2011; Eluru et al., 2008).

Injury factors provide a description of injuries resulting from the accident. The injury information recorded is based on medical examinations carried out by the insurance company during the period in which victims are recovering from their injuries. Injuries resulting from a collision are stated by judicial decision, or agreed upon between parties (insurer and victim), based on both medical reports provided by parties and forensic examinations. The medical examinations have to be made in accordance with a legislative medical scale in force since 1995. The medical scale describes 475 injuries and provides severity point scores for each injury. The motor financial compensation for permanent injuries is then assessed in function of the severity scores (for more details, see Santolino, 2010; Boucher and Santolino, 2010). The average number of injuries in the sample was 1.55 injuries per victim involved in a motor collision. 
Table 1. Description of variables and statistics

\begin{tabular}{|c|c|c|c|c|c|c|c|}
\hline Variable & Label & Description & $\mathrm{N}$ & Mean & SD & Min. & Max. \\
\hline \multicolumn{8}{|c|}{ Dependent variables } \\
\hline$y_{1}$ & $\begin{array}{l}\text { Hospital } \\
\text { admission }\end{array}$ & 1 if victim is admitted to hospital; 0 otherwise. & 16,081 & 10.124 & 0.329 & 0 & 1 \\
\hline$y_{2}$ & Hospital stay & Length of hospital stay (number of days on natural logarithmic scale) & 1,999 & 2.014 & 1.208 & 0 & 6.215 \\
\hline \multicolumn{8}{|c|}{ Regressors } \\
\hline \multicolumn{8}{|c|}{ General factors } \\
\hline$x_{1}$ & \multicolumn{2}{|c|}{ At-fault driver age Age of the at-fault driver (divided by 100). } & 16,081 & 10.412 & 0.144 & 0.14 & 40.990 \\
\hline$x_{2}$ & Victim age & Age of the victim (divided by 100 ). & 16,081 & 10.383 & 0.167 & 0 & 0.980 \\
\hline$x_{3}$ & $\begin{array}{l}\text { Victim } \\
\text { squared }\end{array}$ & Victim age squared (divided by 10000). & 16,081 & 10.175 & 0.150 & 0 & 0.960 \\
\hline$x_{4}$ & Gender & 1 if the injured victim is male; 0 otherwise. & 16,081 & 10.455 & 0.498 & 0 & 1 \\
\hline$x_{5}$ & Driver & 1 if the injured victim was the driver; 0 otherwise. & 16,081 & 10.510 & 0.500 & 0 & 1 \\
\hline$x_{6}$ & Passenger & 1 if the injured victim was the passenger; 0 otherwise. & 16,081 & 10.373 & 0.483 & 0 & 1 \\
\hline$x_{7}$ & Pedestrian/Cyclis & st 1 if the injured was a non-motorized road user; 0 otherwise. & 16,081 & 10.117 & 0.321 & 0 & 1 \\
\hline \multicolumn{8}{|c|}{ Factors related to the injured body region } \\
\hline$x_{8}$ & Head & 1 if injury located in head; 0 otherwise. & 16,081 & 10.129 & 0.336 & 0 & 1 \\
\hline$x_{9}$ & Neck & 1 if injury located in neck; 0 otherwise. & 16,081 & 10.699 & 0.458 & 0 & 1 \\
\hline$x_{10}$ & Upper torso & 1 if injury located in upper torso (thorax/dorsal); 0 otherwise. & 16,081 & 10.250 & 0.433 & 0 & 1 \\
\hline$x_{11}$ & Lower torso & 1 if injury located in lower torso (abdomen/lumbar); 0 otherwise. & 16,081 & 10.193 & 0.395 & 0 & 1 \\
\hline$x_{12}$ & Upper extremitie & s 1 if injury located in upper extremities; 0 otherwise. & 16,081 & 10.257 & 0.437 & 0 & 1 \\
\hline$x_{13}$ & Lower extremitie & $s 1$ if injury located in lower extremities; 0 otherwise. & 16,081 & 10.238 & 0.426 & 0 & 1 \\
\hline$x_{14}$ & Multiple regions & 1 if multiple body regions; 0 otherwise. & 16,081 & 10.063 & 0.243 & 0 & 1 \\
\hline \multicolumn{8}{|c|}{ Factors related to the nature of the injury } \\
\hline$x_{15}$ & Wound & 1 if open wound. 0 otherwise. & 16,081 & 10.077 & 0.267 & 0 & 1 \\
\hline$x_{16}$ & Fracture & 1 if fracture; 0 otherwise. & 16,081 & 10.174 & 0.379 & 0 & 1 \\
\hline$x_{17}$ & Contusion & 1 if contusion; 0 otherwise. & 16,081 & 10.542 & 0.498 & 0 & 1 \\
\hline$x_{18}$ & Sprain/strain & 1 if sprain/strain; 0 otherwise. & 16,081 & 10.738 & 0.440 & 0 & 1 \\
\hline$x_{19}$ & Abrasion & 1 if abrasion/ burn; 0 otherwise. & 16,081 & 10.023 & 0.151 & 0 & 1 \\
\hline$x_{20}$ & Internal injury & 1 if internal injury (nerves. blood vessels. etc.); 0 otherwise. & 16,081 & 10.087 & 0.282 & 0 & 1 \\
\hline
\end{tabular}

Injuries described in the legislative scale are classified according to their nature and the body location in order to reduce the number of injuries on the legal scale into a manageable number of diagnostic categories, inspired by the diagnostic matrix of the International Classification of Diseases (ICD)-9-CM codes developed by Barell et al. (2002). Specifically, a two-dimensional array is used to describe each injury. The first element indicates the location of the injury, while the second records its type. Seven factors are related to the region of the body that was injured and six factors to the nature of the injuries. In comparison with Barell's matrix classification, the number of factors related to the location of injuries was reduced to a simpler classification in order to make identification of the injury location easier for non-medical practitioners (for instance, police officers at the crash scene). As regards the factors related to the injury's nature, the 
Internal injury category records information from the Internal, Blood vessels and Nerves categories of the Barell matrix, due to the low frequency of the last two categories (less than $0.5 \%)$. Low frequency was also the reason for excluding the Amputations and Crush categories from the regression model. All the injury factors are included in the regression as binary variables which take the value 1 if the characteristic is observed and zero otherwise. Victims may suffer more than injury and, therefore, factors are not mutually exclusive.

\section{Results}

\subsection{Hausman test results}

Prior to analysing coefficient estimates it is necessary to test whether the Heckman two-step estimates of $\beta$ are consistent and, therefore, reliable. This was done by first computing the Hausman test. As previously indicated, the hypothesis testing involves a semi-parametric estimation of the model (1), which leads to consistent estimates in both of the hypotheses. However, a $K$ value must be selected to approximate the unknown function $h\left(\hat{v}_{i}\right)$ in the semiparametric method. Figure 2 shows the semi-parametric estimation of $h\left(\hat{v}_{i}\right)$ for $K=3, K=4, K=5$ and $K=6$.

Figure 2. Power series estimation of $\hat{\hat{\lambda}}_{i}=\boldsymbol{h}\left(\hat{v}_{i}\right)$ for $K=3, K=4, K=5$ and $K=6$

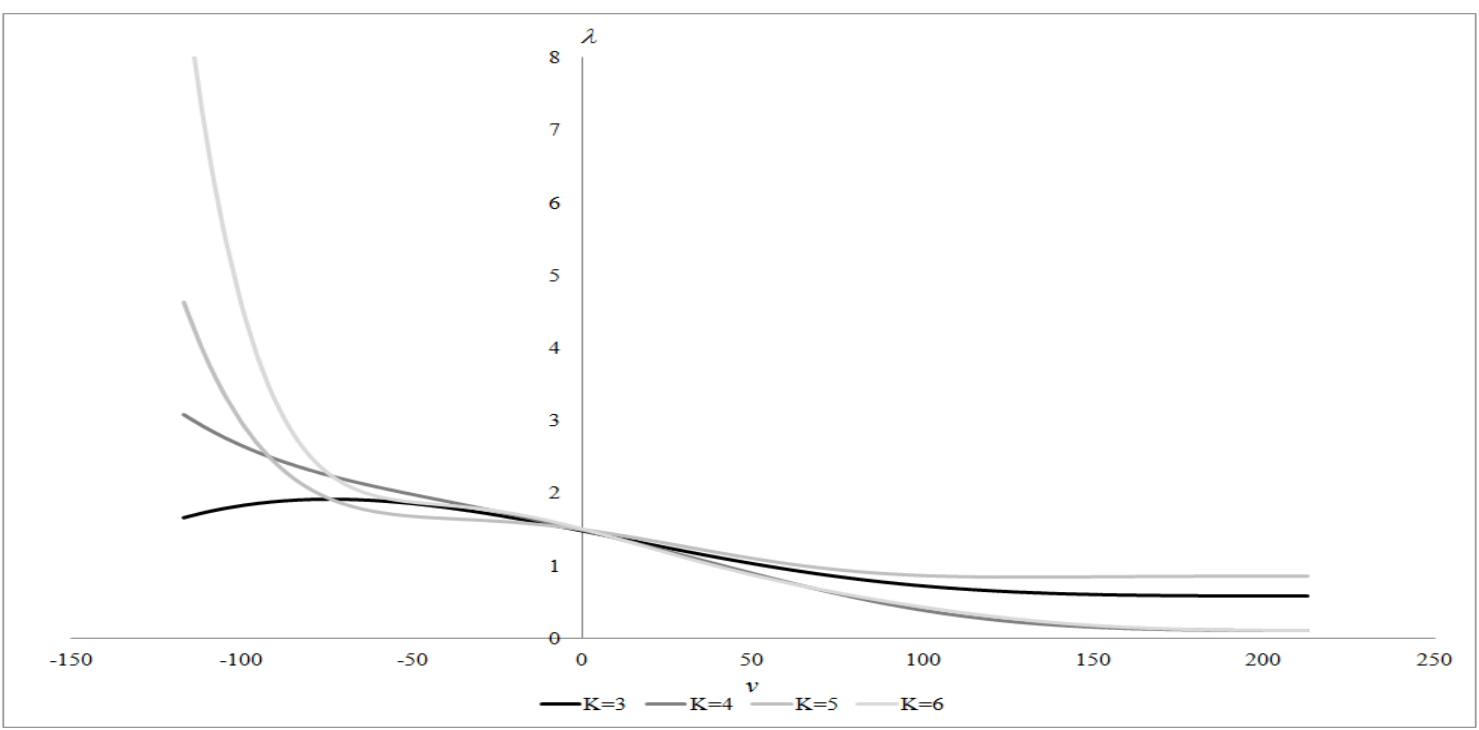


Note that the shape of the function is more flexible for larger $K$ values. This is because the influence of the sample information increases with $K$. Additionally, the resulting approximation is a monotonic decreasing function when $K=4, K=5$ and $K=6$. Similarly, a monotonic decreasing function is obtained if a Probit model is applied to estimate $h\left(\hat{v}_{i}\right)$. However, the resulting approximation is not a monotonic decreasing function when the function is approximated by a second-order power series $(K=3)$. Consequently, the analysis is performed for $K=4, K=5$ and $K=6$. Table 2 shows the results of the Hausman test. In all cases the null hypothesis $\left[H_{0}: \lambda=\phi\left(z^{\prime} \hat{\gamma}\right) / \Phi\left(z^{\prime} \hat{\gamma}\right)\right]$ cannot be rejected at the $5 \%$ significance level. We therefore conclude that the Heckit estimator of the model (1) is consistent.

Table 2. Results of the Hausman test

\begin{tabular}{ccc}
$\boldsymbol{K}$ value & Hausman statistic value & $\boldsymbol{p}$-value \\
\hline 4 & 9.596 & 0.962 \\
5 & 8.098 & 0.986 \\
6 & 7.662 & 0.990 \\
\hline
\end{tabular}

\subsection{Coefficient estimates}

The two-step Heckman estimates of the generalized Tobit regression model are shown in Table 3. Note that the covariance coefficient $\sigma_{12}$ is significantly different from zero at the $10 \%$ significance level ( $p$-value $=0.064)$. This shows that the endogeneity assumption is realistic for these data, which means that the decision to admit a victim to hospital is not independent of the length of the stay in hospital once the victim is admitted. ML estimates are provided in the Annex (Table A1) for comparison purposes. 
Table 3. Heckman two-step estimates and standard errors ( $p$-values in parenthesis) of the generalized Tobit

\section{regression}

\begin{tabular}{|c|c|c|c|c|c|c|c|}
\hline \multirow[b]{2}{*}{ Variable } & \multirow[b]{2}{*}{ Label } & \multicolumn{3}{|c|}{ Hospital admission } & \multicolumn{3}{|c|}{ Length of hospital stay } \\
\hline & & Coeff. & Estim. & Std. Error & Coeff. & Estim. & Std. Error \\
\hline & Intercept & $V_{0}$ & -0.981 & $\begin{array}{r}0.102 \\
(<0.001)\end{array}$ & $\beta_{1}$ & 0.509 & $\begin{array}{r}0.526 \\
(0.332)\end{array}$ \\
\hline$x_{1}$ & At-fault driver age & $Y_{1}$ & -0.171 & $\begin{array}{r}0.109 \\
(0.116)\end{array}$ & $\beta_{1}$ & -0.250 & $\begin{array}{r}0.176 \\
(0.157)\end{array}$ \\
\hline$x_{2}$ & Victim age & $\gamma_{2}$ & -1.234 & $\begin{array}{r}0.396 \\
(0.002)\end{array}$ & $\beta_{2}$ & 0.058 & $\begin{array}{r}0.646 \\
(0.928)\end{array}$ \\
\hline$x_{3}$ & Victim age squared & $\gamma_{3}$ & 1.235 & $\begin{array}{r}0.438 \\
(0.005)\end{array}$ & $\beta_{3}$ & 0.904 & $\begin{array}{r}0.704 \\
(0.199)\end{array}$ \\
\hline$x_{4}$ & Gender & $Y_{4}$ & 0.186 & $\begin{array}{r}0.034 \\
(<0.001)\end{array}$ & $\beta_{4}$ & 0.133 & $\begin{array}{r}0.071 \\
(0.061)\end{array}$ \\
\hline$x_{6}$ & Passenger $\left(^{*}\right)$ & $Y_{6}$ & 0.149 & $\begin{array}{r}0.038 \\
(<0.001)\end{array}$ & $\beta_{6}$ & 0.189 & $\begin{array}{r}0.073 \\
(0.010)\end{array}$ \\
\hline$x_{7}$ & Pedestrian/Cyclist( ${ }^{*}$ ) & $Y_{7}$ & 0.221 & $\begin{array}{r}0.049 \\
(<0.001)\end{array}$ & $\beta_{7}$ & 0.064 & $\begin{array}{r}0.089 \\
(0.469)\end{array}$ \\
\hline$x_{8}$ & Head & $Y_{8}$ & 0.483 & $\begin{array}{r}0.047 \\
(<0.001)\end{array}$ & $\beta_{8}$ & 0.437 & $\begin{array}{r}0.121 \\
(<0.001)\end{array}$ \\
\hline$x_{9}$ & Neck & $\gamma_{9}$ & -0.576 & $\begin{array}{r}0.061 \\
(<0.001)\end{array}$ & $\beta_{9}$ & -0.420 & $\begin{array}{r}0.169 \\
(0.013)\end{array}$ \\
\hline$x_{10}$ & Upper torso & $V_{10}$ & 0.187 & $\begin{array}{r}0.043 \\
(<0.001)\end{array}$ & $\beta_{10}$ & 0.202 & $\begin{array}{r}0.074 \\
(0.006)\end{array}$ \\
\hline$x_{11}$ & Lower torso & $Y_{11}$ & 0.339 & $\begin{array}{r}0.047 \\
(<0.001)\end{array}$ & $\beta_{11}$ & 0.431 & $\begin{array}{r}0.103 \\
(<0.001)\end{array}$ \\
\hline$x_{12}$ & Upper extremities & $Y_{12}$ & 0.015 & $\begin{array}{r}0.038 \\
(0.688)\end{array}$ & $\beta_{12}$ & -0.164 & $\begin{array}{r}0.058 \\
(0.005)\end{array}$ \\
\hline$x_{13}$ & Lower extremities & $V_{13}$ & 0.198 & $\begin{array}{r}0.040 \\
(<0.001)\end{array}$ & $\beta_{13}$ & 0.407 & $\begin{array}{r}0.074 \\
(<0.001)\end{array}$ \\
\hline$x_{14}$ & Multiple regions & $\gamma_{14}$ & 0.105 & $\begin{array}{r}0.059 \\
(0.077)\end{array}$ & $\beta_{14}$ & 0.284 & $\begin{array}{r}0.097 \\
(<0.004)\end{array}$ \\
\hline$x_{15}$ & Wound & $Y_{15}$ & 0.106 & $\begin{array}{r}0.051 \\
(0.037)\end{array}$ & $\beta_{15}$ & -0.020 & $\begin{array}{r}0.077 \\
(0.793)\end{array}$ \\
\hline$x_{16}$ & Fracture & $Y_{16}$ & 0.887 & $\begin{array}{r}0.040 \\
(<0.001)\end{array}$ & $\beta_{16}$ & 0.740 & $\begin{array}{r}0.220 \\
(0.001)\end{array}$ \\
\hline$x_{17}$ & Contusion & $Y_{17}$ & -0.512 & $\begin{array}{r}0.044 \\
(<0.001)\end{array}$ & $\beta_{17}$ & -0.714 & $\begin{array}{r}0.131 \\
(<0.001)\end{array}$ \\
\hline$x_{18}$ & Sprain/strain & $Y_{19}$ & -0.237 & $\begin{array}{r}0.059 \\
(<0.001)\end{array}$ & $\beta_{18}$ & -0.412 & $\begin{array}{r}0.102 \\
(<0.001)\end{array}$ \\
\hline$x_{19}$ & Abrasion & $Y_{20}$ & -0.496 & $\begin{array}{r}0.101 \\
(<0.001)\end{array}$ & $\beta_{19}$ & -0.082 & $\begin{array}{r}0.200 \\
(0.681)\end{array}$ \\
\hline$x_{20}$ & Internal injury & $Y_{21}$ & 0.635 & $\begin{array}{r}0.043 \\
(<0.001)\end{array}$ & $\beta_{20}$ & 0.573 & $\begin{array}{r}0.150 \\
(<0.001)\end{array}$ \\
\hline & & & & & $\sigma_{12}$ & 0.610 & $\begin{array}{r}0.328 \\
(0.064)\end{array}$ \\
\hline & & & & & $\sigma_{2}$ & 1.191 & \\
\hline
\end{tabular}

$\mathrm{N}=16,081$.

$\left({ }^{*}\right)$ Driver is the base category. 
In the road safety literature the driver's age is traditionally associated with the severity of collisions. According to our results, however, the age of the at-fault driver did not have explanatory power as regards the probability of being admitted to hospital and the subsequent length of hospitalization. This is consistent with the results of Tay (2006), who found that increasing the number of licenses issued to ageing drivers did not significantly increase the number of fatal crashes. Here we also tested a quadratic relationship, including as a regressor a variable recording the squared age of the driver. However, the coefficients were not significantly different from zero and the squared age variable was withdrawn in order to achieve a parsimonious model.

Four of the six coefficients of the variables related to victim attributes were statistically significant. The factor associated with the victim's gender showed significant positive coefficients in both equations, especially in the first regression. This means that males injured in a collision were more likely to be hospitalized after the crash than were females, and their average recovery stay in hospital was also longer. Therefore, males seem to suffer more serious injuries than do females, a finding that is consistent with the results of Tay and Rifaat (2007) and Valent et al. (2002). As regards age, there was a quadratic relationship between the victim's age and the probability of being hospitalized. Specifically, young and older victims were more likely to be admitted to hospital than were middle-aged victims, with the inflexion point being around the age of 50 years. From this age on, the probability of hospitalization increased with increasing ages. A previous study by Newgard (2008) similarly found that young and old victims were more likely to be seriously injured, and that the risk for serious injury rose more steeply after the age of 50 . The positive relationship between age and severity is traditionally associated with the greater fragility of elder victims (Li et al., 2003), whereby physical decline would be intensified from the age of fifty onwards.

The type of victim also determines the probability of hospitalization and the length of stay. Compared with drivers, we found that passengers were more likely to be admitted and also to have longer recovery periods in hospital. Other studies also suggest that passengers sustain more serious injuries. Hutchinson (1986) showed that passengers were more seriously injured than drivers in non-overturning accidents, while Hill and Boyle (2006) found that front passengers were 1.1 times more likely to be seriously injured than were drivers. Regarding non-motorized road users, Pucher and Dijstra (2003) estimated that pedestrians were 23 times more likely to be killed than were car occupants in the USA, with cyclists being 12 times more likely to be killed than car occupants. Here we found that both pedestrians and cyclists were more likely to be hospitalized after a collision than were drivers. This is an expected result due to the lack of 
protective elements for mitigating the impact suffered by non-motorized road users. In the event they were admitted, however, there were no significant differences between non-motorized road users and drivers as regards the recovery period in hospital.

In relation to the injury location factors, they almost all showed significant coefficients. Head injuries, followed by those located in the lower torso and the lower extremities, were the injuries which had the strongest positive effect on the probability of being admitted to hospital and on the recovery duration of in-patient motor victims. Previous studies that link severity and injury location support these results. For example, Norin et al. (1997) showed that head injuries were predominant at higher levels of disability, accounting for $40 \%$ of injuries. They also found that while abdomen injuries were more common at higher disability levels, leg injuries were stable across all disability levels. In the same context Fildes et al. (1994) reported that one third of severe crashes involve lower limb injuries to front seat occupants in frontal crashes.

Two injury location factors (Neck and Upper extremities) showed negative coefficients. Thus, neck injuries were negatively related with the probability of being hospitalized and with recovery stay length. Note that injuries located in the neck are the most frequent motor injuries (Table 1) and include mild injuries such as whiplash. The Upper extremities factor only had one significant coefficient. Indeed, injuries located in the upper extremities had no explanatory power as regards the probability of being hospitalized. In the event of admission, however, the expected length of hospital stay was lower for victims with upper extremity injuries. Norin et al. (1997) found that injuries to the neck and arms account for almost $40 \%$ of injuries at lower levels of disability, although they represent fewer than $5 \%$ at higher disability levels.

Finally, hospitalization and recovery duration are also explained by the nature of the injuries, as indicated by the significance of the associated coefficients. Fractures and internal injuries increased both the likelihood of being admitted to hospital and the expected recovery period as an in-patient. By contrast, minor injuries such as contusions, sprains and strains were negatively related to the likelihood of hospitalization and the length of hospital stay. Wounds and abrasions did have an influence on the probability of being admitted to hospital, but not on the length of stay. In fact, while wound injuries increased the probability of hospitalization, this decreased when the victim suffered abrasions as a result of the collision. One explanation for the negative effect of abrasions on the hospitalization likelihood would be that most of these injuries are minor abrasions for which first aid only is required. Similar findings have been reported by other authors. Peek-Asa et al. (2011) showed that in the USA motor-injured teenagers with fractures, internal injuries or intracranial injuries were associated with both higher hospital charges and longer 
lengths of hospital stay. Thygerson et al. (2011) found that fracture and wound injuries accounted for only a fifth of visits to emergency departments but almost two thirds of hospitalizations of injured drivers. By contrast, bruises and abrasions were much more frequent causes of emergency department visits than of hospitalizations. To conclude, fractures and internal injuries, followed by wounds, seem to be the most serious types of injuries in terms of hospital admission and/or length of hospital stay.

\section{Conclusion}

Motor traffic accidents are the leading mechanism of hospitalizations in Europe. Most of the road safety literature analysing the factors which influence the length of hospital stay is based on hospital data and, therefore, the results are limited to motor victims who were admitted to hospital. Here a generalized Tobit regression model was applied to analyse jointly the factors that influence both the likelihood of being admitted to hospital after a motor collision and the length of hospital stay in the event of admission. These two processes were shown to be statistically dependent and, therefore, biased estimates would be obtained if they were modelled separately. Although the reliability of Tobit estimates depends on distributional hypotheses, these are seldom tested (to the best of our knowledge, they have never been tested in road safety applications). Here the consistency of parameter estimates was tested by means of semi-parametric techniques, which did not reject the hypothesis of normality of errors.

The age, gender and type of victim, as well as the location and nature of injuries, were found to be factors that influence the likelihood of being admitted to hospital and/or the length of hospital stay required to recover from injuries sustained in a motor collision. These findings are of particular interest for road safety policy makers, since the analysis of factors that explain hospitalization can be used to target road safety policies so as to reduce the hospitalization rate and length of hospital stay of motor victims. For instance, fractures and injuries located in the head are associated with higher hospitalization rates and longer recovery periods in hospital. A priority for policy makers should therefore be to identify and reduce the types of collisions associated with these injuries. The present analysis can also help policy planners to tackle the motor injury problem not only from the viewpoint of the severity of disabilities caused by collisions but also in terms of the financial consequences borne by society, since hospital charges may be measured financially. Finally, understanding the relationship between hospital admissions and length of hospital stay for motor victims is also of great relevance to medical practitioners, since collisions are a major cause of hospitalizations. 


\section{References}

Abdel-Aty, M., Chen, C., Schott, J., 1998. An assessment of the effect of driver age on traffic accident involvement using log-linear models. Accident Analysis and Prevention, 30, 851-861.

Amemiya, T., 1984. Tobit models: a survey. Journal of Econometrics, 24, 3-61.

Anastasopoulos, P., Tarko, A., Mannering, F., 2008. Tobit analysis of vehicle accident rates on interstate highways. Accident Analysis and Prevention, 40, 768-775.

Barell, V., Aharonson-Daniel, L., Fingerhut, L.A, Mackenzie, E.J., Ziv, A., Boyko, V., Abargel, A., Avitzour, M., Heruti, R., 2002. An introduction to the Barell body region by nature of injury diagnosis matrix. Injury Prevention, 8, 91-96.

Boucher, J.-P., Santolino, M., 2010. Discrete distributions when modeling the disability severity score of motor victims. Accident Analysis and Prevention, 42, 6, 2041-2049.

Cameron, A., Trivedi, P., 2005. Microeconometrics. Cambridge: Cambridge University Press.

Chong, S., Poulos, R., Olivier, J., Watson, W., Grzebieta, R., 2010. Relative injury severity among vulnerable non-motorised road users: Comparative analysis of injury arising from bicycle-motor vehicle and bicycle-pedestrian collisions. Accident Analysis and Prevention, 42, 290-296.

Delen, D., Sharda, R., Bessonov, M., 2006. Identifying significant predictors of injury severity in traffic accidents using a series of artificial neural networks. Accident Analysis and Prevention 38, 434-444.

Eluru, N., Bhat, C., Hensher, D., 2008. A mixed generalized ordered response model for examining pedestrian and bicyclist injury severity level in traffic crashes. Accident Analysis and Prevention, 40, 1033-1054.

Evans, L., 2001. Female compared with male fatality risk from similar physical impacts. The Journal of Trauma: Injury, Infection, and Critical Care, 50, 281-288.

Farah, H., Bekhor, S., Polus, A., 2009. Risk evaluation by modeling of passing behavior on twolane rural highways. Accident Analysis and Prevention, 887-894.

Fildes, B., Lane, J., Lenard, J., Vulcan, A.P, 1994. Passenger cars and occupant injury: Side impact crashes. Federal Office of Road Safety, Report CR 134.

Forman, J., Lopez-Valdes, F., Pollack, K., Heredero-Ordoyo, R., Molinero, A., Mansilla, A., Fildes, B., Segui-Gomez, M., 2011. Injuries among powered two-wheeler users in eight European countries: A descriptive analysis of hospital discharge data. Accident Analysis and Prevention, doi:10.1016/j.aap.2011.02.020.

Goldstein, J.P., 1986. The effect of motorcycle helmet use on the probability of fatality and the severity of head and neck injuries. Evaluation Review, 10, 355-375.

Greene, W.H., 1981. Sample Selection Bias as a Specification Error: Comment. Econometrica, 49, 795-798. 
Guria, J., 1990. Length of hospitalization-An indicator of social costs of disabilities from traffic injuries. Accident Analysis and Prevention, 22, 4, 379-389.

Hagist, C., Kotlikoff, L.J., 2009. Who's going broke? Comparing healthcare costs in ten OECD countries. Hacienda Pública Española / Revista de Economía Pública, 188, 55-72.

Heckman, J. J., 1976. The Common Structure of Statistical Models of Truncation, Sample Selection and Limited Dependent Variables and a Simple Estimator for Such Models. Annals of Economic and Social Measurement, 5, 475-492.

Heckman, J. J., 1979. Sample Selection as a Specification Error. Econometrica, 47, 153-161.

Hill, J., Boyle, L. 2006. Assessing the relative risk of severe injury in automotive crashes for older female occupants. Accident Analysis and Prevention, 38, 148-154.

Huang, H., Chin, H.-C., Haque, M.-M., 2008. Severity of driver injury and vehicle damage in traffic crashes at intersections: a Bayesian hierarchical analysis. Accident Analysis and Prevention, 40, 45-54.

Hutchinson, T., 1986. Statistical modelling of injury severity, with special reference to driver and front seat passenger in single-vehicle crashes. Accident Analysis and Prevention, 18, 157-167.

Klein, R., Spady, R., 1993. An Efficient Semiparametric Estimator for Binary Response Models. Econometrica, 61, 387-421.

Kockelman, K.M., Kweon, Y.-J., 2002. Driver injury severity: an application of ordered probit models. Accident Analysis and Prevention 34, 313-321.

Lee, L.-F., 1984. Tests for the bivariate normal distribution in econometric models with selectivity. Econometrica, 52, 4, 843-863.

Li, G., Braver, E., Chenb, L.-H., 2003. Fragility versus excessive crash involvement as determinants of high death rates per vehicle-mile of travel among older drivers. Accident Analysis and Prevention, 35, 227-235.

Lucchetti, R., Pigini, C., 2011. Conditional Moment Tests For Normality in Bivariate Limited Dependent Variable Models: a Monte Carlo Study. Quaderni di Recerca, 357, Dipartimiento di Economia-Università Politecnica delle Marche.

Machlin, S. R., Carper, K., 2007. Expenses for Inpatient Hospital Stays 2004. Statistical Brief \#164. Agency for Healthcare Research and Quality. Rockville. Md.

Mashtare Jr., T., Hutson, A., 2011. Utilizing the Flexibility of the Epsilon-Skew-Normal Distribution for Tobit Regression Problems. Communications in Statistics-Theory and Methods, 40, 408-423.

Neyens, D., Boyle, L., 2008. The influence of driver distraction on the severity of injuries sustained by teenage drivers and their passengers. Accident Analysis and Prevention, 2008, 254-259.

Newey, W.K., 1987. Specification tests for distributional assumptions in the Tobit model, Journal of Econometrics, 34, 124-145.

Newey, W.K., 1999. Consistency of two-step sample selection estimators despite misspecification of distribution. Economics Letters, 63, 129-132. 
Newey, W.K., 2009. Two-step series estimation of sample selection models. The Econometrics Journal, 12, S217-S229.

Newgard, C., 2008. Defining the "older" crash victim: The relationship between age and serious injury in motor vehicle crashes. Accident Analysis and Prevention, 40, 1498-1505.

Newgard, C., Lewis, R., Kraus, J., John McConnell, J., 2005. Seat position and the risk of serious thoracoabdominal injury in lateral motor vehicle crashes. Accident Analysis and Prevention, 37, 668-674.

Norin, H., Kraff, M., Korner, J., Nygren, A., Tingvall, C., 1997. Injury severity assessment for Car Occupants in Frontal Impacts, Using Disability Scaling. Journal of Clinical Epidemiology, 50, 95103.

O'Donnell, C.J., Connor, D.H., 1996. Predicting the severity of motor vehicle accident injuries using models of ordered multiple choice. Accident Analysis and Prevention 28, 739-753.

Peek-Asa, C., Yanga, J., Ramireza, M., Hamanna, C., Cheng, G., 2011. Factors affecting hospital charges and length of stay from teenage motor vehicle crash-related hospitalizations among United States teenagers, 2002-2007. Accident Analysis and Prevention, 43, 595-600.

Pucher, J., Dijkstra, L., 2003. Promoting safe walking and cycling to improve public health: lessons from The Netherlands and Germany. American Journal of Public Health, 93, 1509-1516.

Rifaat, S., Tay, R., 2009. Effects of street patterns on injury risks in two-vehicle crashes. Transportation Research Record: Journal of the Transportation Research Board, 2102, 61- 67.

Santolino, M., 2010. Determinants of the decision to appeal against motor bodily injury judgements made by Spanish trial courts. International Review of Law \& Economics, 30, 37-45.

Segui-Gomez, M., Martinez-Gonzalez, M.A., de Irala. J., Ewert. U., 2008. Injury-related hospitalizations in Europe 2004. European Center for Injury Prevention, Universidad de Navarra.

Smith, K., Cummings, P., 2004. Passenger seating position and the risk of passenger death or injury in traffic crashes. Accident Analysis and Prevention, 36, 257-260.

Tarko, A., Azam, M.S., 2011. Pedestrian injury analysis with consideration of the selectivity bias in linked police-hospital data. Accident Analysis and Prevention, 43, 1689-1695.

Tay, R., 2006. Ageing drivers: Storm in a teacup? Accident Analysis and Prevention, 38, 112-121.

Tay, R., Rifaat, S., 2007. Factors contributing to the severity of intersection crashes. Journal of Advanced Transportation 41, 245-265.

Thygerson, S., Merrill, R., Cook, L., Thomas, A., 2011. Comparison of factors influencing emergency department visits and hospitalization among drivers in work and nonwork-related motor vehicle crashes in Utah, 1999-2005. Accident Analysis and Prevention, 43, 209-213.

Tobin, J., 1958. Estimation of relationships for limited dependent variables. Econometrica, 26, 2436.

Valent, F., Schiava, F., Savonitto, C., Gallo, T., Brusaferro, S., Barbone, F., 2002. Risk factors for fatal road traffic accidents in Udine, Italy. Accident Analysis and Prevention 34, 71-84. 
Llista Document de Treball

List Working Paper

WP 2011/19 "Factors affecting hospital admission and recovery stay duration of in-patient motor victims in Spain” Santolino, M.; Bolancé, C. and Alcañiz, M.

WP 2011/18 "Why do municipalities cooperate to provide local public services? An empirical analysis” Bel, G.; Fageda, X. and Mur, M.

WP 2011/17 "The "farthest" need the best. Human capital composition and development-specific economic growth” Manca, F.

WP 2011/16 “Causality and contagion in peripheral EMU public debt markets: a dynamic approach” Gómez-Puig, M. and Sosvilla-Rivero, S.

WP 2011/15 “The influence of decision-maker effort and case complexity on appealed rulings subject to multicategorical selection” Santolino, M. and Söderberg, M.

WP 2011/14 “Agglomeration, Inequality and Economic Growth: Cross-section and panel data analysis” Castells, D.

WP 2011/13 “A correlation sensitivity analysis of non-life underwriting risk in solvency capital requirement estimation” Bermúdez, L.; Ferri, A. and Guillén, M.

WP 2011/12 “Assessing agglomeration economies in a spatial framework with endogenous regressors” Artis, M.J.; Miguélez, E. and Moreno, R.

WP 2011/11 “Privatization, cooperation and costs of solid waste services in small towns” Bel, G; Fageda, X. and Mur, M.

WP 2011/10 "Privatization and PPPS in transportation infrastructure: Network effects of increasing user fees" Albalate, D. and Bel, G.

WP 2011/09 "Debating as a classroom tool for adapting learning outcomes to the European higher education area” Jiménez, J.L.; Perdiguero, J. and Suárez, A.

WP 2011/08 “Influence of the claimant's behavioural features on motor compensation outcomes” Ayuso, M; Bermúdez L. and Santolino, M.

WP 2011/07 “Geography of talent and regional differences in Spain” Karahasan, B.C. and Kerimoglu E.

WP 2011/06 “How Important to a City Are Tourists and Daytrippers? The Economic Impact of Tourism on The City of Barcelona” Murillo, J; Vayá, E; Romaní, J. and Suriñach, J.

WP 2011/05 “Singling out individual inventors from patent data” Miguélez,E. and Gómez-Miguélez, I.

WP 2011/04 “¿La sobreeducación de los padres afecta al rendimiento académico de sus hijos?” Nieto, S; Ramos, R.

WP 2011/03 “The Transatlantic Productivity Gap: Is R\&D the Main Culprit?” Ortega-Argilés, R.; Piva, M.; and Vivarelli, M.

WP 2011/02 “The Spatial Distribution of Human Capital: Can It Really Be Explained by Regional Differences in Market Access?” Karahasan, B.C. and López-Bazo, E

WP 2011/01 "If you want me to stay, pay”. Claeys, P and Martire, F

WP 2010/16 "Infrastructure and nation building: The regulation and financing of network transportation infrastructures in Spain (1720-2010)”Bel,G

WP 2010/15 “Fiscal policy and economic stability: does PIGS stand for Procyclicality In Government Spending?” Maravalle, A ; Claeys, P.

WP 2010/14 “Economic and social convergence in Colombia” Royuela, V; Adolfo García, G. 
WP 2010/13

WP 2010/12

WP 2010/11

WP 2010/10

WP 2010/09

WP 2010/08

WP 2010/07

WP 2010/06

WP 2010/05

WP 2010/04

WP 2010/03

WP 2010/02

WP 2010/01

WP 2009/26

WP 2009/25

WP 2009/24

WP 2009/23

WP 2009/22

WP 2009/21

WP 2009/20

WP 2009/19

WP 2009/18

WP 2009/17

WP 2009/16

“Symmetric or asymmetric gasoline prices? A meta-analysis approach” Perdiguero, J.

“Ownership, Incentives and Hospitals” Fageda,X and Fiz, E.

"Prediction of the economic cost of individual long-term care in the Spanish population” Bolancé, C; Alemany, R ; and Guillén M

“On the Dynamics of Exports and FDI: The Spanish Internationalization Process” Martínez-Martín, $\mathrm{J}$.

“Urban transport governance reform in Barcelona” Albalate, D ; Bel, G and Calzada, J.

“Cómo (no) adaptar una asignatura al EEES: Lecciones desde la experiencia comparada en España” Florido C. ; Jiménez JL. and Perdiguero J.

"Price rivalry in airline markets: A study of a successful strategy of a network carrier against a lowcost carrier” Fageda, X ; Jiménez J.L. ; Perdiguero , J.

"La reforma de la contratación en el mercado de trabajo: entre la flexibilidad y la seguridad" Royuela V. and Manuel Sanchis M.

"Discrete distributions when modeling the disability severity score of motor victims” Boucher, J and Santolino, M

"Does privatization spur regulation? Evidence from the regulatory reform of European airports . Bel, G. and Fageda, X.”

“High-Speed Rail: Lessons for Policy Makers from Experiences Abroad”. Albalate, D ; and Bel, G.” "Speed limit laws in America: Economics, politics and geography”. Albalate, D ; and Bel, G.”

"Research Networks and Inventors’ Mobility as Drivers of Innovation: Evidence from Europe” Miguélez, E. ; Moreno, R. ”

”Social Preferences and Transport Policy: The case of US speed limits” Albalate, D.

”Human Capital Spillovers Productivity and Regional Convergence in Spain”, Ramos, R ; Artis, M.; Suriñach, J.

“Human Capital and Regional Wage Gaps”,López-Bazo,E. Motellón E.

"Is Private Production of Public Services Cheaper than Public Production? A meta-regression analysis of solid waste and water services” Bel, G.; Fageda, X.; Warner. M.E.

“Institutional Determinants of Military Spending” Bel, G., Elias-Moreno, F.

“Fiscal Regime Shifts in Portugal” Afonso, A., Claeys, P., Sousa, R.M.

"Health care utilization among immigrants and native-born populations in 11 European countries. Results from the Survey of Health, Ageing and Retirement in Europe” Solé-Auró, A., Guillén, M., Crimmins, E.M.

"La efectividad de las políticas activas de mercado de trabajo para luchar contra el paro. La experiencia de Cataluña” Ramos, R., Suriñach, J., Artís, M.

“Is the Wage Curve Formal or Informal? Evidence for Colombia” Ramos, R., Duque, J.C., Suriñach, $\mathrm{J}$.

“General Equilibrium Long-Run Determinants for Spanish FDI: A Spatial Panel Data Approach” Martínez-Martín, J.

“Scientists on the move: tracing scientists' mobility and its spatial distribution” Miguélez, E.; Moreno, R.; Suriñach, J. 
WP 2009/15

WP 2009/14

WP 2009/13

WP 2009/12

WP 2009/11

WP 2009/10

WP 2009/09

WP 2009/08

WP 2009/07

WP 2009/06

WP 2009/05

WP 2009/04

WP 2009/03

WP 2009/02

WP 2009/01

WP 2008/16

WP 2008/15

WP 2008/14

WP 2008/13

WP 2008/12

WP 2008/11

WP 2008/10

WP 2008/09

WP 2008/08

WP 2008/07
“The First Privatization Policy in a Democracy: Selling State-Owned Enterprises in 1948-1950 Puerto Rico” Bel, G.

“Appropriate IPRs, Human Capital Composition and Economic Growth” Manca, F.

“Human Capital Composition and Economic Growth at a Regional Level” Manca, F.

“Technology Catching-up and the Role of Institutions” Manca, F.

“A missing spatial link in institutional quality” Claeys, P.; Manca, F.

“Tourism and Exports as a means of Growth” Cortés-Jiménez, I.; Pulina, M.; Riera i Prunera, C.; Artís, M.

"Evidence on the role of ownership structure on firms' innovative performance” Ortega-Argilés, R.; Moreno, R.

“¿Por qué se privatizan servicios en los municipios (pequeños)? Evidencia empírica sobre residuos sólidos y agua” Bel, G.; Fageda, X.; Mur, M.

"Empirical analysis of solid management waste costs: Some evidence from Galicia, Spain”

Bel, G.; Fageda, X.

“Intercontinental fligths from European Airports: Towards hub concentration or not?” Bel, G.; Fageda, X.

"Factors explaining urban transport systems in large European cities: A cross-sectional approach" Albalate, D.; Bel, G.

"Regional economic growth and human capital: the role of overeducation" J.; Artís, M.

“Regional heterogeneity in wage distributions. Evidence from Spain” Motellón, E.; López-Bazo, E.; El-Attar, M.

"Modelling the disability severity score in motor insurance claims: an application to the Spanish case” Santolino, M.; Boucher, J.P.

“Quality in work and aggregate productivity” Royuela, V.; Suriñach, J.

"Intermunicipal cooperation and privatization of solid waste services among small municipalities in Spain” Bel, G.; Mur, M.

"Similar problems, different solutions: Comparing refuse collection in the Netherlands and Spain" Bel, G.; Dijkgraaf, E.; Fageda, X.; Gradus, R.

"Determinants of the decision to appeal against motor bodily injury settlements awarded by Spanish trial courts” Santolino, M

"Does social capital reinforce technological inputs in the creation of knowledge? Evidence from the Spanish regions” Miguélez, E.; Moreno, R.; Artís, M.

“Testing the FTPL across government tiers” Claeys, P.; Ramos, R.; Suriñach, J.

“Internet Banking in Europe: a comparative analysis” Arnaboldi, F.; Claeys, P.

“Fiscal policy and interest rates: the role of financial and economic integration” Claeys, P.; Moreno, R.; Suriñach, J.

“Health of Immigrants in European countries” Solé-Auró, A.; M.Crimmins, E.

“The Role of Firm Size in Training Provision Decisions: evidence from Spain” Castany, L.

"Forecasting the maximum compensation offer in the automobile BI claims negotiation process" Ayuso, M.; Santolino, M. 
WP 2008/06 “Prediction of individual automobile RBNS claim reserves in the context of Solvency II” Ayuso, M.; Santolino, M.

WP 2008/05 "Panel Data Stochastic Convergence Analysis of the Mexican Regions” Carrion-i-Silvestre, J.L.; German-Soto, V.

WP 2008/04 "Local privatization, intermunicipal cooperation, transaction costs and political interests: Evidence from Spain” Bel, G.; Fageda, X.

WP 2008/03 "Choosing hybrid organizations for local services delivery: An empirical analysis of partial privatization” Bel, G.; Fageda, X.

WP 2008/02 “Motorways, tolls and road safety. Evidence from European Panel Data” Albalate, D.; Bel, G.

WP 2008/01 “Shaping urban traffic patterns through congestion charging: What factors drive success or failure?” Albalate, D.; Bel, G.

WP 2007/19 “La distribución regional de la temporalidad en España. Análisis de sus determinantes” Motellón, E.

WP 2007/18 “Regional returns to physical capital: are they conditioned by educational attainment?” López-Bazo, E.; Moreno, R.

WP 2007/17

"Does human capital stimulate investment in physical capital? evidence from a cost system framework” López-Bazo, E.; Moreno, R.

WP 2007/16 “Do innovation and human capital explain the productivity gap between small and large firms?” Castany, L.; López-Bazo, E.; Moreno, R.

WP 2007/15 “Estimating the effects of fiscal policy under the budget constraint” Claeys, P.

WP 2007/14 "Fiscal sustainability across government tiers: an assessment of soft budget constraints” Claeys, P.; Ramos, R.; Suriñach, J.

WP 2007/13 "The institutional vs. the academic definition of the quality of work life. What is the focus of the European Commission?” Royuela, V.; López-Tamayo, J.; Suriñach, J.

WP 2007/12 “Cambios en la distribución salarial en españa, 1995-2002. Efectos a través del tipo de contrato” Motellón, E.; López-Bazo, E.; El-Attar, M.

WP 2007/11 “EU-15 sovereign governments’ cost of borrowing after seven years of monetary union” GómezPuig, M..

WP 2007/10 “Another Look at the Null of Stationary Real Exchange Rates: Panel Data with Structural Breaks and Cross-section Dependence” Syed A. Basher; Carrion-i-Silvestre, J.L.

WP 2007/09 "Multicointegration, polynomial cointegration and I(2) cointegration with structural breaks. An application to the sustainability of the US external deficit” Berenguer-Rico, V.; Carrion-i-Silvestre, J.L.

WP 2007/08 "Has concentration evolved similarly in manufacturing and services? A sensitivity analysis” RuizValenzuela, J.; Moreno-Serrano, R.; Vaya-Valcarce, E.

WP 2007/07 "Defining housing market areas using commuting and migration algorithms. Catalonia (Spain) as an applied case study” Royuela, C.; Vargas, M.

WP 2007/06 "Regulating Concessions of Toll Motorways, An Empirical Study on Fixed vs. Variable Term Contracts” Albalate, D.; Bel, G.

WP 2007/05 “Decomposing differences in total factor productivity across firm size” Castany, L.; Lopez-Bazo, E.; Moreno, R.

WP 2007/04 “Privatization and Regulation of Toll Motorways in Europe” Albalate, D.; Bel, G.; Fageda, X.

WP 2007/03 "Is the influence of quality of life on urban growth non-stationary in space? A case study of Barcelona” Royuela, V.; Moreno, R.; Vayá, E. 
WP 2007/02

WP 2007/01

WP 2006/10

WP 2006/09

WP 2006/08

WP 2006/07

WP 2006/06

WP 2006/05

WP 2006/04

WP 2006/03

WP 2006/02

WP 2006/01 “Sustainability of EU fiscal policies. A panel test” Claeys, P.

"Research networks and scientific production in Economics: The recent spanish experience” Duque, J.C.; Ramos, R.; Royuela, V.

"Term structure of interest rate. European financial integration” Fontanals-Albiol, H.; Ruiz-Dotras, E.; Bolancé-Losilla, C.

"Patrones de publicación internacional (ssci) de los autores afiliados a universidades españolas, en el ámbito económico-empresarial (1994-2004)” Suriñach, J.; Duque, J.C.; Royuela, V.

“Supervised regionalization methods: A survey” Duque, J.C.; Ramos, R.; Suriñach, J.

“Against the mainstream: nazi privatization in 1930s germany” Bel, G.

"Economía Urbana y Calidad de Vida. Una revisión del estado del conocimiento en España” Royuela, V.; Lambiri, D.; Biagi, B.

"Calculation of the variance in surveys of the economic climate” Alcañiz, M.; Costa, A.; Guillén, M.; Luna, C.; Rovira, C.

"Time-varying effects when analysing customer lifetime duration: application to the insurance market” Guillen, M.; Nielsen, J.P.; Scheike, T.; Perez-Marin, A.M.

"Lowering blood alcohol content levels to save lives the european experience” Albalate, D.

"An analysis of the determinants in economics and business publications by spanish universities between 1994 and 2004” Ramos, R.; Royuela, V.; Suriñach, J.

"Job losses, outsourcing and relocation: empirical evidence using microdata” Artís, M.; Ramos, R.; Suriñach, J. 
